\title{
"Heading" and NeCK InJURIES in Soccer: A Review OF Biomechanics and Potential Long-Term Effects
}

\author{
Michael J. Mehnert, MD, Thomas Agesen, MD, and Gerard A. Malanga, MD
}

Background: Although soccer has a lower injury rate than does American football, injuries to the head and neck do occur. Indeed, soccer is classified as a contact sport. The potential for cervical injuries from the maneuver known as "heading" are of particular concern. This review provides a synopsis of soccer-related head and neck injuries, an overview of the biomechanics of trauma, and a rational approach to evaluating patients.

Objective: This review was conducted to assess and evaluate existing literature on the biomechanics of the act of heading in soccer and the potential for acute and longterm injury to the head and neck.

Design: The resulting work is based on literature searches of the PubMed and Medline databases, textbook reviews, and bibliographies of articles and textbooks obtained during the search. Findings from several

Soccer, known as football everywhere in the world except the United States, is undoubtedly one of the world's most popular team sports. In the United States alone it is estimated that 12.5 to 18.2 million people participate in this sport. A global estimate by the Fédération Internationale de Football Association (1)

From: Department of Physical Medicine and Rehabilitation, University of Medicine and Dentistry of New Jersey, Newark, NJ; and Sports, Spine Orthopedic Medicine Rehabilitation, Kessler Institute of Rehabilitation, West Orange, NJ.

Address Correspondence:

Michael J. Mehnert, MD

Dept. of Physical Medicine and Rehabilitation

30 Bergen Street, ADMC 101

Newark, NJ 07103

E-mail: mehnermi@umdnj.edu

Disclaimer: There was no external funding in preparation of this manuscript.

Conflict of interest: None

Manuscript received on $7 / 18 / 2005$

Revision submitted on $8 / 15 / 2005$

Accepted for publication 9/1/2005 studies were summarized and critiqued. Biomechanics, anatomy, pathophysiology, and their relation to the act of heading in soccer were also synthesized into the discussion. Relevant studies of athletes in other sports where activity can affect the neck and head in a manner similar to heading were also considered.

Results: The act of heading in soccer involves the athlete's entire body, and studies have used electromyography to define the activity of neck musculature during heading. The majority of head and neck injuries in soccer occur secondary to impacts other than those that occur during heading, however, rare case reports of serious injury exist. Degenerative bony changes in the cervical spine of soccer players have been noted in a few studies, but the connection with heading is not well established. Data from research in other sports, particularly American foot- ball and rugby, suggest a predisposition to degenerative disease of the neck secondary to axial loading mechanisms; the exact relevance of these studies to heading and soccer is unclear.

Conclusions: The complex biomechanics of heading in soccer are not completely defined, especially with regard to long-term effects on the neck and cervical spine. Existing studies of long-term effects suggest a predisposition to degenerative changes of the cervical spine, though they are somewhat limited, even when coupled with data regarding athletes in other sports. Further research in this area is needed with studies that assess biomechanical forces under simulated play conditions and control for impacts and stresses to the neck and spine that occur from non-heading activity.

Keywords: Soccer, heading, neck injuries, football has reported the number of people worldwide who regularly play at approximately 250 million, with that number growing every year.

Despite this popularity, there seems to be a relative deficit of literature about the exact biomechanics and complications (both immediate and long-term) of neck trauma resulting from a maneuver in this sport known as "heading". By contrast, there are significant data on cervical injury in American football. Perhaps this is due to the fact that, relatively speaking, soccer has a fairly low injury rate, especially when compared to American football (2). Nonetheless, soccer is classified by the American Academy of Pediatrics as a contact sport, and there is a risk of head and neck injury. Concussions account for a fairly high percentage of injuries in soccer players, and have been reported to be as much as $3.2 \%$ and $2.8 \%$ of all injuries in men's and women's soccer, with slight- ly higher numbers among soccer-playing youths (2). As a result, increasing attention is given to the possible role of heading in mild traumatic brain injury. Most would argue that a differentiation must be made between head injuries from all causes in soccer vs. possible cumulative effects from proper heading. Similarly the question arises as to the effects of heading on the structures in the neck, and to what extent they are affected by routine play and proper technique as opposed to incidental collisions or falls.

\section{Role of Heading}

The act of heading the ball is a common activity in soccer and is a maneuver which, for the most part, has no counterpart in other sports. Studies by Smodlaka (3) and Sortland and Tysvaer (4) estimate that professional soccer players play the ball with the head five to six times per game, on average. This can result in 
as many as 5,250 game situation impacts over the course of a 15-year professional career (3), not to mention the occurrences in practice as players master heading techniques and hone their skills.

Heading the ball is an exciting activity in soccer, and it is involved in both offensive and defensive play. All players on the field can play the ball with the head, though it is less commonly done by goalkeepers, likely because they have much more freedom to use their arms and hands than do other players. Heading the ball is used as a means of clearing or intercepting the ball, gaining control, passing and attempting to score a goal. "Clearing" headers involve the player impacting the ball to produce maximum force to drive the ball back in the direction from which it came. A "flick-on" header involves the player lightly tapping the ball with the head only to re-direct or change the trajectory of ball flight to move the ball out of a defender's reach. "Heading for goal" is a shooting header performed when a ball crossed from the corner is redirected on goal by snapping the head and neck laterally to intercept ball flight and change the trajectory of the ball by approximately 90 degrees.

Players head the ball while on the ground, when running, jumping vertically, and even while diving. Heading is indeed a skill, and requires coordination and practice. For the most part it is an active process (though incidental or unexpected head-to-ball contact does occur) that involves coordinated movement of the entire body.

\section{EPIDEMIOLOGY}

Among the types of play in soccer (dribbling, shooting, passing), along with other means of challenging for the ball such as "tackling," heading has been identified as an action that carries "significant risk" (5). Head and neck injuries account for approximately $10 \%$ of soccer injuries (6) though numbers in the literature range from $4 \%$ to $22 \%$ (7). A study of reported injuries occurring in 485 players has reported the vast majority of injuries occur in the lower extremities, with most of these being foot injuries. Head injuries accounted for $11.3 \%$ and neck injuries for $1.2 \%$ of the injuries in these players (8). In an Italian study of 208 patients, $22.7 \%$ of all head and neck injuries were related to sports. Of these, approximately $65 \%$ were caused by soccer (9) with the majority be- ing caused by contact with another player, and only $2.3 \%$ caused by contact with the ball.

\section{BIOMECHANICS}

In published analyses of heading, the maneuver has been broken down based on whether the athlete's approach to the ball is from a standing or running position $(7,10)$ and also by the preparation, impact and follow-through phases of the act itself (11). In general the movement involves the entire body, with the desired effect being an active impact of the high forehead/frontal bone (the part of the player's head above the eyebrows and below the hairline) with the soccer ball during forward motion of the head, neck, and trunk. An important aspect of heading is the timing of impact, both to ensure that the body is prepared to receive the impact in a way that allows stability of the head and neck, and also to ensure that the ball contacts the head as it is moving forward which provides momentum to exert a tactically useful force on the ball. Heading, therefore, requires that the athlete's eyes be open in order to track the ball as much as possible.

In preparing for heading the ball, the player is trying to position himself geographically on the field to play the ball, and is also trying to ensure correct timing for impact. In so doing he or she will generally employ either a standing, running, and/or jumping approach. Mawdsley (10) found that the activity of the head and neck in heading was greater in standingjumping headers as opposed to those with running-jumping approaches, and postulated that there was a decreased need for neck muscle activity to provide a propulsive force on the ball as there would be an increased momentum from the running and jumping activity (10).

In heading there is an initial active movement of the trunk backward into extension. The body and head are extended as one large unit, with the chin tucked in towards the chest (11). This extension and backwards movement enables the player to then move these structures forward with greater velocity at impact. The power for this movement is generated by the movement of the trunk and action at the hip flexors $(10,11)$. The arms and legs of the athlete play a varying role in the maneuver, depending upon the technique employed and the proximity of other players. If multiple players are going for the ball, players' arms and elbows are up to protect their head and face. If no other players are challenging for the header, the arms have more of a passive role and are generally extended forward both to maintain balance and to offset the backwards movement of the head and torso. When these structures accelerate forward, the arms are rapidly brought down to the player's sides. The role of the legs in heading the ball in midair is obvious, and in these instances the legs are drawn backwards and upwards in preparation for impact with the ball (11). After impacting with the ball, the player generally continues moving forward and resumes play on the field.

Studies investigating the motion of the head and neck with respect to injury during heading have concluded that injury depends more on the acceleration of the head than on the applied force, and that this acceleration may be reduced by effectively contracting the neck musculature (11). In addition, several studies in traumatic brain injury have concluded that rotational acceleration is more dangerous than is linear acceleration of the head (12). The neck musculature plays an obvious role in stabilizing the headneck-torso complex $(7,10,11)$ in an effort to reduce the angular acceleration as well as to better control the ball. It would make sense, then, that when players are "prepared" to head the ball, the soft tissue structures in the neck more effectively reduce the impact force by controlling rotational acceleration of the head. Despite the complex movements of the athlete's entire body in heading, the head, neck, and torso effectively act as one unit with increased mass to subsequently limit potentially dangerous angular acceleration. It has been reported that relative to the body, the velocity of the head should essentially be zero (7).

The neck muscles have also been described as having a role in generating power and dissipating energy during heading (15). In 1989, Shapiro and Frankel (16) suggested that there is a role of the muscles in the neck as a source of energy dissipation and shock absorption. It is not clear from available literature how much of the force of impact received by the head is conveyed to the soft tissue structures of the neck, or how much is dissipated by the neck muscles and transmitted to the bony structures and joints of the cervical spine. For the most part, players perform head- 
ing during play on a regular basis without evidence of any injury to the cervical spine. The forces are likely being dissipated by some combination of the paravertebral musculotendinous tissues, the elastic intervertebral discs, and the bony joints and structures.

Bauer et al (17) performed a study on 15 "elite female college athletes" using surface electrodes to monitor sternocleidomastoid activity and trapezius muscle activation during heading under different conditions. The theory was tested that the sternocleidomastoids activate first to pull the head forward to increase velocity just prior to impact, and the electromyography (EMG) analysis verified that the sternocleidomastoids do initiate first. Also interesting was that activation occurs earlier in a jumping header approach. These results suggest that there indeed is some additional forward acceleration of the head, and that the headneck-torso do not create a completely rigid lever arm. The data also demonstrated that the trapezius muscles activate just before impact. This is thought to be a part of the stabilization role involving co-contracture of the musculature in the head, neck, and shoulders in an attempt to absorb the shock of impact (15). Furthermore, the trapezius muscles do remain active longer than do the sternocleidomastoids, a fact thought to be due to a role for the trapezius muscles in decelerating the head and maintaining stability of the head and neck. Overall the muscles were active from between 500 milliseconds (ms) before, to $500 \mathrm{~ms}$ after impact (17).

As Bauer points out, the impact force of the ball and the amount of neck muscle activity are generally regarded as functions of the exact heading technique used and the intended result. For example, it was postulated that a shooting header might not need as much velocity or distance as a clearing header, and thus the action may need to apply less force or dissipate more. Similarly, a shooting header may require more head or neck movement to "fine tune" or aim the shot than does a clearing header. The results did show greater peak and integrated normalized EMG values for jumping than for standing headers for the sternocleidomastoids and trapezius muscles, which contradicts Mawdsley's hypothesis (10) that the opposite may be true. The authors suggest that this may be due to a dependency of muscle activity with regard to heading technique on the incoming ball speed. The study did use a relatively slow ball speed; thus more neck propulsive forces may have been required. It also may be necessary to increase the stability of the neck when jumping to better transmit the force of the body to the ball (18).

Other than the above differences in approach, the data collected in Bauer's 2001 study (17) did not demonstrate a significant difference in muscle activity for header type (shooting, clearing, and passing). Similarly, impact force and impulse data measured using forehead pressure sensor arrays did not reveal significant differences based on technique. A jumping approach, which one might expect to increase the force of heading by increasing momentum (using the mass of the whole body to channel impact) did not result in an increased force. This result is probably due to the fact that players jump to meet the ball at the highest possible point; they do not "jump into" the ball. The authors also offered as one explanation the idea that the players may be developing the greatest forces they can tolerate in essentially every heading situation they encounter, giving similar results across the board. It is worth noting that though the heading maneuvers were not performed in situations that very closely resembled competitive play, the overall model appears to be a useful one for further research of this kind (17).

Impact consists of the initial contact of the ball with the head and deformation of the ball, followed by a recoil phase. The duration of impact has been consistently measured in the range of $10 \mathrm{~ms}$ to $23 \mathrm{~ms}$ assessed using cinematography and accelerometers $(6,7,19)$.

The magnitude of impact acceleration involved in heading a soccer ball has been reported to be as high as more than $20 \mathrm{~g}$ ( $\mathrm{g}$ is a measure of acceleration, where $1 \mathrm{~g}$ is $9.8 \mathrm{~m} / \mathrm{s}^{2}$ ) for ball speeds of approximately 26 miles per hour (mph) (12). In fact, a soccer ball is estimated to attain speeds as high as 120 kilometers per hour (kph) to $130 \mathrm{kph}$ (75 mph to $80 \mathrm{mph}$ ) when kicked with maximum power (20). These parameters can translate into upwards of 2000 newtons (N) of force when striking a player's head (7). When compared with routine impacts during play in American football and hockey, soccer heading impacts had higher peak accelerations (an average of 54.7g) and Head Injury Criteria scores (21).
In general, three different sizes of soccer balls are used in organized play: No. 5 for adults; No. 4 for juniors; and No. 3 for children. The typical ball weighs 14 to $16 \mathrm{oz}$., with smaller balls being lighter and easier to control, and therefore less dangerous. In the past balls were made of leather, although now most balls are made of waterproof, molded synthetics to prevent the ball from retaining water and becoming quite heavy. Wet balls can potentially weigh $20 \%$ more than the ball's dry weight, rendering a wet ball more dangerous to a player upon impact (3). A recent study of soccer ball properties in relation to impact suggests that the mass ratio of the ball to a player's head correlates with increasing angular and linear acceleration differences. According to this principle, players with a "higher" ratio of ballto-head mass may be implicitly at higher risk of injury. Such players would intuitively be women and children as opposed to adult men. However, there is also no significant change in force with different mass ratios, suggesting that acceleration is a better predictor than force for assessing the risk of injury (22).

Newtonian physics describes force as the product of mass and acceleration. By fixing the head with a rigid or stabilized neck, the player is effectively dealing with a larger mass (the torso, neck, and head as one unit), which results in less acceleration of the head for a given force (18). Also, in Mawdsley's description (10) the head moves backwards relative to the trunk at the time of ball impact. This allows for a greater impulse (force applied across time).

Given Newton's law where $\mathrm{F}=\mathrm{m} \mathrm{x}$ a or $\mathrm{F}=\mathrm{mx}$ [change in $\mathrm{v}$ ] $/ \mathrm{t}$ ( $\mathrm{F}$ is force, $\mathrm{m}$ is mass, $a$ is acceleration, $v$ is velocity and $t$ is time), an increased time of impact will result in a decreased force and thus, a less forceful blow to the head $(7,18)$. Though it is useful to consider this theory in describing the biomechanics of impact, recent data suggests that although there is a decrease in angular and linear head acceleration in a two-dimensional model of head impact with a completely rigid vs. a flaccid neck model, there was no significant change in impact time or force (22).

The relationship between duration of impact and the force of the ball correlates with the concept of impulse, which is mechanically defined as $\mathrm{I}=\mathrm{Ft}$ (where $\mathrm{I}$ is impulse, $\mathrm{F}$ is force and $\mathrm{t}$ is time period over which a force is applied). There 
seems to be more emphasis on examining this parameter in the recent literature, as is noted in the above study on ball properties (22). The difference that Mawdsley (10) identified between a standing-jumping header and a running-jumping header also translates well into Newton's laws. The running jump allows a player to attain greater upward velocity and to couple this with forward movement of the body, increasing the momentum of the ball at impact (7).

The last phase of a heading maneuver can be thought of as follow-through and/or recovery. During this stage there is the prolonged activity of the trapezius muscles relative to the sternocleidomastoids to control the deceleration of the head. It is interesting to note that in the experimental model employed by Bauer et al (17) the sternocleidomastoid "turned off" even quicker after impact when the athlete "aimed" the ball at the ground, as this attempt requires the chin be tucked in prior to impact to direct the ball downwards $(6,17)$.

\section{InJURIES - Mechanism of InJURy, Acute and Chronic Sequelae}

Of the potential injuries in soccer directly related to routine and proper heading of the ball, cervical strain of the neck musculature or sprains of the ligamentous structures may be the most common problem. Overall these injuries are the most common sports-related neck injuries (23) and are likely under-diagnosed and under-reported. In heading a soccer ball these can result from repetitive stresses or improper technique (which could apply forces improperly or fail to dissipate them), as well as to situations where a player is not prepared to impact the ball with his or her head (14).

Cervical contusions are also a common sports-induced injury, but these are intuitively less likely in soccer, as they generally result from direct impact to the neck. Muscle strains can result from a blow to the head during a muscular contraction (which occurs almost by definition in heading). The applied force creates an eccentric contraction that can cause tensile failure in the muscle, often at the myotendinous junction (23). Once serious pathology is ruled out, these injuries are generally considered minor and tend to eventually resolve with or without treatment. The athlete with "less than a full pain-free range of cervical motion" or with neurological symptoms, should be protected from further sports activity and undergo appropriate evaluation (24).

There is also the potential for more serious injury in soccer, but it is a rare phenomenon when described in the setting of heading alone without head impact with the ground, a fixed object (such as a goalpost), or another player. A case report of central cord syndrome after heading secondary to vascular injury from hyperextension of the cervical spine was published in 1978 (25), though little information is given about the player's background. Tysvaer (14) published a report of cervical disc herniation in a soccer athlete, again with limited background on the athlete, though there is documentation of no prior trauma. Three cases of spinal injuries from professional soccer play in Scotland were reported in 1982, but these injuries were not discussed in significant detail (26). Smodlaka (3) brought to light a reported death due to head injury from heading that occurred in 1925; however this was due to brain injury.

With regard to potential acute injury to the cervical spine in heading, another obvious concern is for an axial loading injury similar to that seen in American football and well-documented by Torg as an entity named "spear tackler's spine" (27,28). A 1993 study (28) examined 15 players with histories of spear tackling opponents; all were listed on the National Football Head and Neck Injury Registry. These 15 players had sustained cervical spine injury and also demonstrated findings of congenital cervical stenosis, radiological evidence of pre-existing posttraumatic c-spine changes, and persistent changes in curvature of the c-spine.

The technique of spear tackling involves an impact that distributes an axial load to the straightened cervical spine. This can lead to stenosis, deviations of the normal cervical spinal lordosis, compression fractures, disk bulges/herniations, ligamentous instability, and possibly neurological damage from spinal cord injury. Axial loading ("spearing") effectively creates a segmented column when the neck is slightly flexed, thus reversing normal lordosis and creating a straight spine. The axial impacts sustained during sports impair bending, and result in loading of the spinal structures. With a great enough impact force the spine may buckle into flexion and result in serious spinal and neurological injury $(28,29)$. This loss of lordo- sis and straightening of the cervical spine had been reported to occur at 30 degrees of flexion. With an axial force application, the energy is transmitted along the longitudinal axis of the spine and is not dissipated by the paravertebral muscles (30).

The usefulness of the research done by Torg $(27,28)$ with respect to soccer heading is not clear. Soccer heading is a complex activity that involves the legs, hips, trunk, and neck muscles. Most authors have reported that the impact with the ball occurs with the neck in some degree of flexion $(6,7,10)$, but based on the areas of the head that strike the ball in proper heading, there should not be routine axial loading with a loss of lordosis and impact with the spine straight. In addition there is contact with a non-anchored lightweight object as opposed to another player's center of mass, although there may be large amounts of energy transmitted with contact with the ball. This provides the player an opportunity for follow-through, or "striking through," which is not seen in spear tackling.

In addition to axial loading, cervical hyperflexion and hyperextension continue to receive attention as mechanisms of injury in rugby, soccer, and gymnastics (30). For example, initially c-spine injuries in American football were thought to be unique to the helmet design and a proposed "guillotine mechanism." This mechanism resulted in hyperextension injury as a result of impingement of the posterior rim of the helmet on the posterior cervical spine because of initial frontal impact (31); however, this theory was found to be invalid by Carter and Frankel (32). Thus, these mechanisms are also of limited value in an examination of soccer heading.

Chronic changes and complications of the cervical spine with respect to heading in soccer are also not well researched. After the age of 40, degenerative changes of the c-spine are a normal finding even in individuals without known head or neck injury (33). It is widely accepted dogma that any sort of repetitive trauma to the neck or spine may accelerate degenerative changes of the moving segments. Some evidence of this phenomenon has been published regarding degenerative changes in professional Norwegian soccer players (34). In this study, 43 players underwent clinical exams and cervical spine radiographs. The authors reported that compared with men of similar age groups 
the onset of degenerative changes among the 43 athletes occurred 10-20 years earlier with a slightly increased frequency. The greatest difference in the degree of degeneration between athletes and controls was seen in the intervertebral joints of the upper cervical region. Nine of the 43 players had a history of cervical complaints. Five of these nine were self-classified as "headers."

In the study of Norwegian soccer players, 25 of the 43 players $(60 \%)$ also had decreased range of motion of the cervical spine, with a marked reduction noted in 18 of them. Also noteworthy was that five of the players in this study had healed cervical fractures in the lateral masses, without knowledge of specific injuries (as compared to one individual in the control group). In three players the fracture was unilateral in the third vertebra, in one player fractures were bilateral in the fourth vertebra, and in the fifth player the fracture was bilateral in the sixth vertebra. Interestingly, four of these five players were 57 years or older.

Though 10 out of a total of 12 players in this study who were described as "headers" had clinical symptoms, the number was not statistically significant. The study suggests increased degenerative disease with earlier progression in soccer players, but does not lend much support to heading as a predisposing factor. The author proposes that perhaps players who feel they head the ball frequently have improved technique, which decreases their risk. More studies on a larger scale would be beneficial in this area, specifically with regard to heading the ball.

To again draw a comparison with the data from Torg $(27,28)$ regarding progressive development of "spear tackler's spine" in soccer players would require further imaging and follow-up during an athlete's career. Interestingly, the authors of the study of Norwegian soccer players (34) describe the blow in heading as mainly a hyperextension and compression strain which may result in injury to the vertebral body, the intervertebral joints, and the discs in the lower part of the cervical spine.

More recently, a study by Kartal et al (35) examined 30 male soccer players (categorized as either "active" or "veteran" players) and 30 age-matched controls. The study evaluated neck range of motion, extension moment and presence of degenerative changes via cervical dynamometry and dynamic radiological and magnetic resonance imaging (MRI) techniques. They noted a tendency towards early degenerative changes in soccer players with a lower-than-average cervical range of motion. It was postulated that these changes were due to high- and/or low-impact recurrent trauma to the cervical spine from heading the ball.

Other studies in other sports have looked at head impacts and their longterm effects on the cervical spine. Tysvaer (7) has previously commented on one such study, that in 1962 (36) assessed the effect of chronic recurrent cervical spine trauma in 6 high-cliff divers in Acapulco, Mexico. These divers performed approximately 100 dives per year from a height of 135 feet. Of the 6 divers, 4 had fractures in the cervical spine as compared with no fractures in controls. Perhaps most intriguing is that the greatest bone changes were found among divers who dived with their hands spread apart and with their head impacting the water full-on, as opposed to those who coned or clasped their hands in front of their head to decrease the impact. These same divers (3 of the 6) had bone bridging anteriorly in the cervical spine. No such changes were found among the 3 who dived with clasped hands (36).

Rugby is yet another contact sport where there is documentation of changes in the cervical spine attributed to regular play. Scher et al (37) have done studies documenting degenerative changes in rugby players like the ones noted by Sortland et al $(4,34)$ in soccer athletes. The cspines of front-line rugby players were also examined via MRI by Berge et al (38). Forty-seven front-line rugby players along with 40 age-matched control subjects were evaluated at different points in their careers. The front-line rugby players showed more early degenerative alterations on MRI scans than did the agematched control subjects. Again, these changes were postulated to be due to repetitive cervical trauma from play.

Another pertinent question arises regarding predisposition to the development of acute or chronic neck pain, regardless of identification of focal injuries. A 1981 study of 128 Norwegian players (13) determined that $5 \%$ of the players reported chronic neck pain as a problem from heading the ball, with this complaint being second only to headache. Some of the literature has suggested that, in gen- eral, athletes are protected against the development of neck pain by virtue of better conditioning, while others have identified sports as a risk factor for neck pain. In a review of physical risk factors for neck pain, Ariens et al (39) concluded that the data on this matter is inconclusive. It is again important to distinguish neck pain from heading from neck pain secondary to sports activity in general; further research is needed in this area.

\section{Risk Factors for Neck Injuries from HEADING}

Obvious risk factors for neck injuries from heading include the athlete's technique and conditioning. When proper technique is used, the neck musculature is rigid and active and the body is prepared for the forces that occur when the ball strikes the head. The number of impacts a player experiences may be related to the risk of injury, but this is not clear, as the concept of practice and improving technique with experience may be relevant. Unprepared impacts of the ball with the head should be avoided. When only examining injuries from proper heading, there is no data that one player's position (except for that of the goalkeeper, perhaps) is at less risk than any other. Finally, athletes should be taught not to fear heading the ball, and they must be instructed on "striking through the ball" as well as on using their trunk and lower leg musculature with heading technique.

Younger players should use appropriately sized balls when learning heading techniques. Queen et al (22) and Schneider and Zernicke (40) have noted the role of mass ratio of the head to the ball in head injury; their findings suggest that there is increased risk of injury in heading if the mass ratio of the head to the ball is low, as is the case for women and children. Along these same lines, proper equipment (i.e. waterproof soccer balls) should also be used (2).

It may be hard for soccer players to imagine using headgear or helmets while playing. However, an analysis of four types of headgear has suggested that some headbands may decrease the peak acceleration of impact at high speeds (41). Though this study did not assess linear vs. rotational acceleration in detail, it has been postulated that headbands may also increase the risk of injury to the neck in the mathematical model and cadaver model. A change in the coefficient 
of friction and an increase in the radius of the player's head were cited as factors which can increase the ball's moment arm and the head's moment of inertia (41). In studying rotational acceleration of the brain in relation to concussion, Gennarelli (42) found that monkeys wearing cervical collars that prevented the head from rotating were less likely to receive concussions than were animals without such restrictions. As opposed to immobilizing the necks of players, it seems logical that conditioning of the neck musculature is a reasonable way to apply this concept on the soccer field.

Funk (43) has published two case reports of athletes playing American football who developed symptoms and were found to have congenital instability of the cervical spine. Though routine screening of athletes is impractical, a thorough clinical evaluation with radiography of the cervical spine should be performed in players with symptoms, particularly adolescents. Torg (44) found that in the absence of instability or symptoms in American football players, developmental narrowing of the cervical canal does not predict or predispose players to neurological injury. Though athletes with irreversible changes who meet the criteria for "spear tackler's spine" should avoid contact sports, it is difficult to translate all of Torg's work with axial loading in American football to soccer.

\section{Conclusions}

The complex biomechanics of heading the ball in soccer and its acute and chronic effects on the necks of players are not yet fully understood. As it is unlikely that the role of heading the ball in soccer will change in the future (especially given the use of the header as a frequent means of scoring), this area will require further research to explore potential safety and injury issues for players. It may be useful to continue to assess more detailed biomechanics with the model employed by Bauer et al (17), hopefully under conditions that approximate actual play. This model, which allows for analysis of impact force, head movement, and surface EMG assessment of muscle activation, is valuable in assessing the biomechanics of heading.

Other long-term effects from proper heading should not be ignored. The potential for cognitive impairment needs to be fully explored. In addition, relatively little is known about how the bony structures of the neck and how they react during impact and immediately afterwards. Chronic changes have been assessed to some degree already with radiographs and MRIs, and these studies should continue to be pursued. More data from players involving the prevalence, incidence, risk factors, and role of heading in the development of neck pain would be beneficial in determining a cause-effect relationship. With regards to the safety of heading and frank spinal cord damage, published literature pertaining to American football is a useful springboard into more research, but is certainly not conclusive.

Equally important is the question as to whether or not repeated trauma or changes to the cervical spine in players can render players more prone to other neck problems, including radiculopathies. It may prove interesting to perform EMG examinations of the neck musculature of players to look for subtle changes in the musculature from early or subclinical radiculopathy.

\section{Author AfFllation:}

\section{Michael J. Mehnert, MD}

Resident

Department of Physical Medicine and Rehabilitation

UMDNJ-New Jersey Medical School

30 Bergen Street, ADMC 101

Newark, NJ 07103

E-mail: mehnermi@umdnj.edu

\section{Thomas Agesen, MD}

Clinical Assistant Professor

Physical Medicine and Rehabilitation UMDNJ-New Jersey Medical School

Mountainside Hospital

$95 \mathrm{Mt}$. Kembel Avenue

Morristown, NJ 07960

\section{Gerard A. Malanga, MD}

Associate Professor, Physical Medicine and Rehabilitation

UMDNJ-New Jersey Medical School

Director, Pain Management

Overlook Hospital

Director, Sports Medicine

Mountainside Hospital

95 Mt. Kembel Avenue

Morristown, NJ 07960

\section{References}

1. FIFA-Survey: Big Count. InfoPlus. FIFA 2000. Zurich. http://images.fifa.com/ images/pdf/IP-199_01E_big-count.pdf

2. Putukian M. Soccer. In Mellion MB, Putukian M, Madden CC (eds). Sports Medicine Secrets. Hanley \& Belfus, Philadelphia, 2003, pp 450-456.

3. Smodlaka VN. Medical aspects of heading the ball in soccer. Phys Sportsmed 1984; 12:127-131.

4. Sortland O, Tysvaer AT. Brain damage in former association football players: An evolution by computed tomography. Neuroradiology 1989; 31:44-48.

5. Rahnama N, Reilly T, Lees A. Injury risk associated with playing actions during competitive soccer. Br J Sports Med 2002; 36: 354-359.

6. Lynch JM, Bauer JA. Acute head and neck injuries. In Garrett WE Jr, Kirkendall DT, Coniguglia SR (eds). The U.S. Soccer Sports Medicine Book. Williams \& Wilkins, Baltimore, 1996, pp 185-190.

7. Tysvaer AT. Head and neck injuries in soccer: Impact of minor trauma. Sports Med 1992; 14:200-213.

8. Muller W. Acute injuries. In Garrett WE Jr, Kirkendall DT, Coniguglia SR (eds). The U.S. Soccer Sports Medicine Book. Williams \& Wilkins, Baltimore, 1996, pp 177184 .

9. Frenguelli A, Ruscito P, Bicciolo G, Rizzo $S$, Massarelli M. Head and neck trauma in sporting activities. J Crani-Maxillo-Fac Surg 1991; 19:178-181.

10. Mawdsley H. A biomechanical analysis of heading. Momentum 1978; 3:30-40.

11. Lynch JM, Bauer JA. Heading. In Garrett WE Jr, Kirkendall DT, Coniguglia SR (eds). The U.S. Soccer Sports Medicine Book. Williams \& Wilkins, Baltimore, 1996, pp 81-85.

12. Naunheim R, Bayly PV, Standeven J, Neubauer JS, Lewis LM, Genin GM. Linear and angular head accelerations during heading of a soccer ball. Med Sci Sports Exerc 2003; 35:1406-1412.

13. Tysvaer A, Storli O. Association football injuries to the brain: A preliminary report. $\mathrm{Br}$ J Sports Med 1981; 15:163-166.

14. Tysvaer AT. Case report: Cervical disc herniation in a football player. Br J Sports Med 1985; 19:43-44.

15. Burslem I, Lees A. Quantification of impact accelerations of the head during the heading of a football. In Reilly T, Lees A, Davids K, Murphy WJ (eds). Science and Football. E \& FN Spon, London, 1988, pp 243-248.

16. Shapiro I, Frankel VH. Biomechanics of the cervical spine. In Nordin M, Frankel VH (eds). Biomechanics of the Musculoskeletal System 1989, Lea \& Febiger, Philadelphia, pp 209-224.

17. Bauer JA, Thomas TS, Cauraugh JH, Kaminski TW, Hass CJ. Impact forces and neck muscle activity in heading by collegiate female soccer players. J Sports Sci 2001; 19: 171-179. 
18. Reid SE, Epstein HM. Physiologic response to impact. J Trauma 1975; 15:150-152.

19. Schneider PG, Lichte $H$. Untersuchungen zur groesse der krafteinwirkung beim kopfballspiel des fussballers. Sportarzut und Sportmedizin 1975; 26:10.

20. Anzil F. The football player's jumping abilities and head playing. In Vecchiet L (ed) First International Congress on Sports Medicine Applied to Football, Rome. February 6-9, 1979; 643-652.

21. Naunheim, RS, Standeven J, Richter C, Lewis LM. Comparison of impact data in hockey, football, and soccer. J Trauma Inj Infect Crit Care 2000; 48:938-941.

22. Queen RM, Weinhold PS, Kirkendall DT, Yu B. Theoretical study of the effect of ball properties on impact force in soccer heading. Med Sci Sports Exerc 2003; 35:20692076.

23. Zmurko MG, Tannoury TY, Tannoury CA, Anderson DG. Cervical sprains, disc herniations, minor fractures and other cervical injuries in the athlete. Clin Sports Med 2003; 22:513-521.

24. Torg JS. Management guidelines for athletic injuries to the cervical spine. Clin Sports Med 1987; 6:53-60.

25. Scoppetta C, Vaccario ML. Central cervical cord syndrome after heading a football. Lancet 1978; 1:1269.

26. Hitchcock ER, Karmi MZ. Sports injuries to the central nervous system. I $R$ Coll Surg Edinburgh 1982; 27:46-49.

27. Torg JS, Truek R, Quedenfeld TC. National football head and neck registry. J Am Med Assoc 1979; 241:1477-1482.

28. Torg JS, Sennett B, Pavlov H, Leventhal MR, Glasgow SG. Spear tackler's spine: An entity precluding participation in tackle football and collision activities that expose the cervical spine to axial energy inputs. Am J Sports Med 1993; 21:640-649.

29. Allen CR, Kang JD. Transient quadipaaresis in the athlete. Clin Sports Med 2002; 21: 15-27.

30. Torg JS, Guille JR, Jaffe S. Injuries to the cervical spine in American football play ers. J Bone Jt Surg Ser A 2002; 84A:112122.

31. Schneider RC, Reifel E, Crisler HO, Oosterbaan BG. Serious and fatal football injuries involving the head and spinal cord. J Am Med Assoc 1961; 117:362-367.

32. Carter DR, Frankel VH. Biomechanics of hyperextension injuries to the cervical spine in football. Am / Sports Med 1984; 8:302307.

33. Gore DR, Sepic SB, Gardner GM. Roentgenographic findings of the cervical spine in asymptomatic people. Spine 1986; 11: 521-524.

34. Sortland O, Tysvaer AT, Storli OV. Changes in the cervical spine in association football players. Br J Sports Med 1982; 16:80-84.

35. Kartal A, Yildiran I, Senkoylu A, Korkusuz F. Soccer causes degenerative changes in the cervical spine. Eur Spine J 2004; 13:7682.

36. Schneider RC, Papo M, Soto Alvarez C. The effects of chronic recurrent spinal trauma in high-diving: A study of Acapulco's divers. J Bone Jt Surg Ser A 1962; 44A:648656.

37. Scher AT. Premature onset of degenerative disease of the cervical spine in rugby players. S Afr Med J 1990; 77:557-558.

38. Berge J, Marque B, Vital J-M, Senegas J, Caille J-M. Age-related changes in the cervical spines of front-line rugby players. $A m$ J Sports Med 1999; 27:422-429.

39. Ariens GAM, van Mechelen W, Bongers PM, Bouter LM, van der Wal G. Physical risk factors for neck pain. Scand J Work Environ Health 2000; 26:7-19.

40. Schneider K, Zernicke RF. Computer stimulation of head impact: Estimation of headinjury risk during soccer heading. Int J Sports Med 1988; 4:358-371.

41. Naunheim R, Ryden A, Standeven J. Genin G, Lewis L, Thompson P, Bayly P. Does soccer headgear attenuate the impact when heading a soccer ball. Acad Emerg Med 2003; 10:85-90.

42. Gennarelli TA. Head injury in man and experimental animals: Clinical aspects. Acta Neurochi Suppl 1983; 32:1-13.

43. Funk Jr. JF, Wells RE. Injuries of the cervical spine in football. Clin Orthop Relat Res 1975; 109:50-58.

44. Torg JS. Cervical spinal stenosis with cord neurapraxia: Evaluations and decisions regarding participation in athletics. Current Sports Medicine Reports 2002; 1:43-46. 